\title{
Learning Mathematics From Home During COVID-19: Insights From Two Inquiry- Focussed Primary Schools
}

\author{
Penelope Kalogeropoulos ${ }^{1 *}$, Anne Roche ${ }^{1}$, James Russo ${ }^{1}$, Sapna Vats ${ }^{2}$, Toby Russo ${ }^{3}$ \\ ${ }^{1}$ Monash University, AUSTRALIA \\ 2 Wooranna Park Primary School, AUSTRALIA \\ ${ }^{3}$ Spensley Street Primary School, AUSTRALIA
}

Received 25 October 2020 • Accepted 27 February 2021

\begin{abstract}
In early 2020, due to the COVD-19 pandemic, Australian schools were closed and students began an unprecedented time of remote learning. The current study aimed to understand how teachers planned and implemented mathematics learning programs for their students, the challenges they encountered, as well as the degree to which their students were motivated or engaged when learning mathematics at home. Two teachers from two Australian primary schools who shared a similar contemporary teaching and learning philosophy emphasising inquiry-based learning were interviewed, and students were surveyed anonymously about their engagement (cognitive, emotional, social and behavioural) when learning mathematics from home. Findings indicated that both teachers were concerned about effectively catering for all students and assessing student progress and engagement with the tasks. Survey data revealed most students displayed positive engagement with remote learning experiences, except for the lack of opportunity to learn mathematics with and from their peers.
\end{abstract}

Keywords: COVID-19, primary education, mathematics, inquiry-based learning, student engagement, remote learning

\section{INTRODUCTION}

Most of 2020, schools in Victoria, Australia moved to learning from home ('remote learning') due to COVID19 restrictions. This was unprecedented and schools needed to make quick decisions about how to best facilitate this, with little time to obtain resources and upskill. Studies conducted early in 2020, internationally and nationally, have shown that teachers were feeling stressed when navigating these changes and were concerned that students' academic and social needs were not being met (Flack, Walker, Bickerstaff, Earle, \& Margetts, 2020; Hamilton, Kaufman, \& Diliberti, 2020).

With regards to mathematics education specifically, there were concerns that learning mathematics away from the school environment may undermine inquirybased approaches to learning mathematics in several ways. First, as noted by Sullivan et al. (2020), explicit explanations followed by repeated practice are conducive to the use of video technology, specifically instructional videos that can be prepared in advance and shared through a weblink. By contrast, inquiry-based approaches to learning mathematics require studentcentred, mathematically rigorous discussions that are built around students' experiences of working on tasks. Such post-task discussions provide teachers with opportunities to highlight connections between mathematical ideas that emerge (Stein, Engle, Smith, \& Hughes, 2008), as well as opportunities for students to learn from one another's strategies (Russo \& Hopkins, 2017). Such a discourse intensive approach to learning mathematics is likely to be dependent on synchronous in-class facilitation. Second, teachers may either anticipate or respond to (potential) negative attitudes towards mathematics and mathematics learning held by some adults in the home environment, and therefore be less willing to pursue tasks that are open-ended, involve students taking risks, and/ or having to navigate the "zone of confusion" (Clarke, Roche, Cheeseman, \& 


\section{Contribution to the literature}

- $\quad$ The current study contributes to the literature through considering the extent to which 'sociomathematical norms' (Yackel \& Cobb, 1996) central to effective inquiry-based mathematics classrooms are translatable to a remote learning setting.

- Some sociomathematical norms, such as providing students with choice over tasks, methods, and the level of challenge, effectively translated. Enacting these norms in turn supported student cognitive, emotional and behavioural engagement in mathematics during remote learning.

- Other norms, in particular, opportunities to work collaboratively in a classroom community and to learn through discourse, were particularly difficult to recreate in a remote learning setting.

Sullivan, 2014). It is worth noting that both these points have received recent empirical support. Specifically, Russo, Bobis, Downton, Livy, and Sullivan (2021) found that primary teachers who had participated in a professional learning program focussed on inquirybased approaches to learning mathematics tended to be reluctant to allow productive struggle in remote learning settings. The two main reasons given for this reluctance were the absence of a teacher-facilitated, synchronous, learning environment and parents' negative attitudes towards struggle when learning mathematics.

Given the temptation to adopt more didactic, teachercentred approaches (Sullivan et al., 2020), and the challenges of primary-aged students interacting with their teacher and peers exclusively through technologymediated platforms (Blackburn, 2020), we may expect student engagement in mathematics to be particularly challenging in remote learning contexts. It is particularly relevant to examine this issue in school contexts where teachers were committed to pursuing inquiry-based approaches to learning mathematics prior to remote learning. Specifically, it is highly unlikely that schools committed to a model of teacher-directed instruction would decide to adopt an inquiry-based approach during remoting learning; however, given the pressures outlined previously, the converse is certainly possible. Consequently, the first three authors, all working as educational academics, invited the fourth and fifth authors, primary school teachers working in environments highly committed to inquiry-based learning in mathematics, to collaborate with them on the current research project. Informed by the literature related to student engagement, the current study aimed to investigate the extent to which primary students reported being engaged with mathematics when learning at home in contexts where teachers had previously been pursuing inquiry-based learning approaches.

\section{TEACHING AND LEARNING DURING THE COVID-19 PANDEMIC}

Studies from the United States have reported on the impact of teaching and learning during the pandemic (Hamilton, et al., 2020; Reich et al., 2020; USA TODAY \& Ipsos, 2020). Reich et al. (2020) interviewed 40 teachers across the United States, in a range of school sectors during 2020, to describe their professional experiences during the pandemic. The study highlighted three main challenges for teachers. These were:

- Teachers struggled to motivate students

- Teachers experienced burnout and loss of their identities as teachers

- Inequalities were exacerbated for students with special needs or from non-well-resourced districts

USA TODAY and Ipsos (2020) reported that many parents $(60 \%)$ and teachers $(86 \%)$ expressed concerns about how students were progressing academically during remote learning. Hamilton et al. (2020) reported teachers were having a harder time doing their job remotely $(83 \%)$ and believed that students were falling behind due to learning from home $(76 \%)$. Also, only $12 \%$ of teachers reported covering all or nearly all of the curriculum they would have covered had face-to-face learning continued, and the authors raised concerns about students' readiness for the next grade level.

Likewise, Australian studies have also found similar difficulties for teachers and students during COVID-19. The findings from an online survey of more than 3500 teachers across Australia and New Zealand in April 2020 described the potential impact of enforced distance teaching and learning during COVID-19 on teachers, children and educational outcomes (Flack et al., 2020). The responses revealed that teachers were "under extraordinary pressure - dealing with unfamiliar technologies and teaching methods, struggling with additional demands for preparation, worrying about the lack of social contact with students and colleagues, and fearing for the educational and psychological welfare of students, particularly those in early primary school" (p. 3 ). Several themes were identified in relation to meeting the needs of students through online learning. The most common concerns were student isolation and their wellbeing. These social needs were ranked higher than a potential learning loss. Teachers were also concerned that the loss of social interaction in the classroom would decrease the effectiveness of their teaching, and 39\% of Australian teachers reported being only somewhat confident or not at all confident in their school's ability to meet students' learning needs online. Related to this $37 \%$ 
of Australian teachers were concerned that students lacked access to the technology or internet, also 36\% and $38 \%$ were concerned that students lacked technology support from a parent or guardian, and learning support from a parent or guardian, respectively. In light of the concerns for students' (and teachers') well-being the study made a range of recommendations one of which was lessoning the learning targets and lowering expectations.

As previously mentioned, students from disadvantaged backgrounds are likely to be more at risk of falling behind during remote learning. Results from PISA in 2018 (Thomson, 2020) compared the home learning environments of low and high socioeconomic status (SES) 15-year-olds in Australia. While 88\% of 15year-olds reported having a quiet place to study at home, this varied from $78 \%$ for low SES to $96 \%$ for advantaged students. Similarly, $84 \%$ of disadvantaged students reported they had a computer at home to use for schoolwork as compared to $99 \%$ for advantaged students. These data did not take into account whether parents and siblings were now working or studying at home, and therefore putting extra strain on students and families to negotiate access to potentially limited devices in the home. Further, parent beliefs and values around the use of technology at home, or students' 'screen time', may add to the complexity of access to devices.

A brief supplied to the Australian Government by The Australian Chief Scientist (Dr Alan Finkel) outlined three factors that moderate the effectiveness of remote learning (Finkel, 2020). These were a) access to digital technology and the internet; b) home learning environment and family support; c) teacher and student readiness and capabilities. Drane Vernon, and O'Shea, (2020) outlined ten recommendations to support the learning of vulnerable children during the COVID-19 pandemic. Relevant to the current study were recommendations that suggested that: students and parents should not be overloaded with downloading multiple applications and platforms; students and parents should not be expected to scan and send through student's work; livestreaming classes for primary students should be no longer than 20 minutes; technologies are chosen based on teachers' and students' skills; and families should be supported by providing internet connectivity and access to devices.

\section{INQUIRY-BASED LEARNING}

The teachers selected for this study (fourth and fifth authors) were from schools that are known for their innovative teaching practices through challenging tasks and inquiry. Inquiry-based learning involves contextualising mathematical learning to support student engagement with authentic problems, and providing opportunities for understanding to be developed through rich mathematical dialogue and exploration (Fielding-Wells \& Makar, 2008). Teachers who embrace inquiry-based learning typically select tasks that aim to promote rich, contextualised understandings instead of rote learning, and are inclined to pursue tasks with a high level of cognitive demand (Boston \& Smith, 2009). Students are required to use selfregulatory skills as they set goals for themselves to complete complex tasks (Fielding-Wells, O'Brien, \& Makar, 2017). Scaffolded inquiry-based approaches have been shown to lead to better student learning outcomes in comparison to explicit instruction and unassisted discovery-based learning - including within mathematics education (Alfieri, Brooks, Aldrich, \& Tenenbaum, 2011). Moreover, inquiry-based learning has been linked to a range of affective student outcomes, including positive attitudes towards academic subjects, self-efficacy, and intrinsic motivation (Russo \& Russo, 2019; Saunders-Stewart, Gyles, \& Shore, 2012). Ryan and Deci (2000) defined intrinsic motivation as "doing something because it is inherently interesting or enjoyable" (p. 55), and this has been shown to be positively associated with mathematics performance (Thomson, De Bortoli, \& Buckley, 2014).

Establishing particular 'sociomathematical norms' (Yackel \& Cobb, 1996) is critical in classrooms that aim to pursue inquiry-based approaches to learning mathematics effectively (Makar \& Fielding-Wells, 2018). Although it is not possible nor desirable to attempt to describe exhaustively the sociomathematical norms relevant to inquiry-based classrooms, some key norms highlighted in the research literature include an emphasis on:

- valuing mathematically different solution approaches and evaluating the efficiency and sophistication of a given solution approach (Yackel \& Cobb, 1996);

- listening to peers and being willing to explain and justify one's solution approach and thinking (Makar, Bakker, \& Ben-Zvi, 2015);

- higher levels of student autonomy and a developing sense that mathematical authority rests within the broader community of learners, rather than solely with the teacher (Yackel \& Cobb, 1996);

- allowing students to make choices about the level at which they access the task (Sullivan \& Mornane, 2014), including if and when they access enabling prompts (Russo, Minas, Hewish, \& McCosh, 2020);

- opportunities to undertake mathematical work in group settings, with an emphasis on collaborative problem solving, making sense of a peer's understanding of a problem, and supporting peers to correct errors in their mathematical thinking (Yackel, Cobb, \& Wood, 1991). 
One of the aims of the current study is to examine the extent to which (re)establishing such sociomathematical norms in a virtual setting may be a barrier to pursuing inquiry-based approaches in remote learning settings.

\section{STUDENT ENGAGEMENT}

Student engagement, including cognitive, emotional and behavioural engagement is fundamental to effective learning, student achievement and well-being (Finn \& Zimmer, 2012; Fredricks, Blumenfeld, \& Paris 2004). Cognitive engagement includes "flexibility in problem solving, preference for hard work, and positive coping in the face of failure" (Fredricks et al, 2004, p. 64). Emotional engagement refers to students' affective reactions that include interest, boredom, happiness, sadness and anxiety (Skinner \& Belmont, 1993). Behavioural engagement includes involvement in learning tasks and behaviours such as effort, persistence, attention and contributing to class discussion (Skinner \& Belmont, 1993). Collectively, these dimensions of engagement have been defined as "an emotional involvement or commitment to some object" (Bempechat \& Shernoff, 2012, p. 317-318). Disengaged students are at risk of lower academic achievement and poorer social outcomes (Angus et al., 2009; Hancock \& Zubrick, 2015).

Research suggests that engagement is malleable. For example, Bishop and Kalogeropoulos (2015) found that mathematics students labelled by their teachers as engaged or disengaged showed a mixture of engaged and disengaged practices across time. Engagement behaviours may be promoted or facilitated by features of the classroom environment (Skinner, 2016). These may include "social relationship, contexts, and tasks [and] pedagogical caring, support from parents and peers, goal structures, autonomy support, school climate, disciplinary and management strategies, and the nature of the academic work" (p. 145). However, the extent to which these exist is likely to differ in a remote learning environment. Shernoff (2013) outlined some of the major differences with the online learning environment as compared to the classroom face-to-face environment. He explained that

seeing one's instructor and peers face to face, students can observe many socially mediated cues that regulate the pace of learning, expectations, and the "culture" of the class. This includes the instructor's feedback to one's own and others' work, [and that this whole class environment] may be the chief mechanism for successfully selfregulating both learning and academic success in the course (p. 316).

However, in the online environment "this selfregulatory environment goes out the window. It becomes the student's responsibility to interact with the course." (p. 316). Shernoff suggested that without sufficient self-regulatory behaviors, real time feedback and social interaction, students may lose motivation, may procrastinate with tasks, may underestimate the time it takes to complete a task, and students who are poorly organised or have competing agendas may fail to perform the task. To increase engagement, he suggested that online tools should be used to increase collaboration, the exchange of ideas, and exploration.

\section{BACKGROUND TO THE STUDY}

During May 2020, all schools in Victoria, Australia moved to learning from home due to COVID-19 restrictions. This was unprecedented and schools needed to make quick decisions about how to best facilitate this, with little time to obtain resources and upskill. The learning from home in the first phase lasted six weeks during second term. Children resumed faceto-face learning in a phased return across the last five weeks of term for students across primary and second schools. Victorian schools were in a unique position in an Australian context, whereby the return to face-to-face learning was followed by a second, longer period of remote learning for all of Term 3 (nine weeks) during the second wave of the pandemic.

Given how rapidly this unfolded we sought insights from two teachers (fourth and fifth authors) at the end of the first phase of remote learning (Term 2) to tell the story about how their respective schools faced the challenge of teaching and learning mathematics in this new environment. During the second phase of remote learning (Term 3), students in the two schools were surveyed through an online platform about their engagement with mathematics when learning from home. We then gathered further insights from the two teachers following the end of the second phase of remote learning, to explore any changes they made and how they responded to the identified challenges.

The current study sought to address the following research questions:

During the COVID-19 induced remote learning period:

1. How did primary schools with inquiry-based [mathematics] learning opportunities adapt to online learning?

2. What challenges did teachers report when planning and implementing mathematics programs during learning from home?

3. How did schools respond to these challenges during the second phase of remote learning in term 3 of 2020 ?

4. To what extent were primary students engaged with mathematics when learning from home? 
Table 1. Frequency of students per grade who completed the Student Engagement Survey

\begin{tabular}{lccccccc}
\hline & Gr1 & Gr2 & Gr3 & Gr4 & Gr5 & Gr6 & Total students \\
\hline \# students & 2 & 9 & 0 & 2 & 11 & 13 & 37 \\
\hline
\end{tabular}

\section{METHOD}

\section{School Demographics and Participants}

Two teachers (Sapna and Toby - fourth and fifth authors) from different primary schools (School A and School B respectively) shared their experiences with setting up mathematics learning at home. These schools were deliberately sought out due to their contrasting demographic profiles, but similar emphasis on inquirybased learning.

Sapna is a Year 2 teacher at a government primary school in the southeastern suburbs of Melbourne. The 369 students attending the school come from racially and culturally diverse backgrounds. Seventy percent of the students have a language background other than English. The school's Index of Community SocioEducational Advantage (ICSEA) percentile is 34, with $44 \%$ of the students belonging to the bottom ICSEA quartile. The school's philosophy focuses on fostering student agency, voice and passions in order to empower students and support them to take risks. It is based on the need to maximise students' options, present and future, so that they might achieve social flexibility, economic well-being, personal satisfaction and empowerment.

Toby teaches a Year 5/6 composite class at a government primary school in the inner northern suburbs of Melbourne, and also occupies the role of learning specialist (pedagogy). Only a small minority (7\%) of the school's 378 students have a language background other than English. On average, students attending the school are from more advantaged backgrounds compared with the country as a whole. Specifically, its ICSEA percentile is 97 , with $76 \%$ of the students belonging to the top ICSEA quartile. The school's philosophy is premised on supporting multiaged inquiry-based learning, providing an environment that empowers and supports students to be skilled, knowledgeable, and caring young people, lifelong learners, and thoughtful citizens.

\section{Students}

Thirty-seven primary students completed the online Student Engagement Survey. Students from Grades 1 and 2 came from School $A(n=11)$ and the students from Grades 4-6 came from School B $(n=26)$. See Table 1 for a breakdown of the number of students per grade.

\section{Data Collection Instruments}

\section{Teacher interviews}

The two participant teachers were interviewed separately by the first author via a Zoom conference meeting following the first phase of remote learning (Term 2). Each interview was recorded and the audio subsequently transcribed. Each teacher was interviewed for around 30 minutes using a semi structured interview protocol. The questions were designed to elicit explanations of how their mathematics program was planned for, designed, and implemented during 'at home' learning, and any challenges they faced in this process. Some illustrative questions included:

1. Could you describe the mathematics learning program that you provided during learning at home?

2. What aspects of learning mathematics at home were similar to the mathematics learning experiences provided typically at school?

3. What challenges did you experience in delivering mathematics learning at home?

4. If you were required to organise a mathematics program for learning at home again, what would you so similarly and what would you do differently?

Due to the free-flowing nature of the semi-structured interviews, the teachers varied in the degree of detail they provided for each question and not all questions on the protocol were explicitly asked. The interview data provided a summary of the most salient decisions each teacher (and their school) made to plan for and implement their mathematics program, as well as describing features of their programs and the challenges they faced.

The two participant teachers provided written responses to questions following the second phase of remote learning (Term 3), where they explored some of the adjustments they made as a result of the challenges faced in the first phase. These questions included:

1. What changes did you make to remote learning in Term 3, compared with Term 2?

2. How were these changes successful in addressing any of the challenges identified following the first phase of remote learning?

\section{Student engagement survey}

Primary students from each of the case study schools were anonymously surveyed online using Qualtrics (online survey platform) to provide insight about their 
Please complete the following sentences.

1. Som etimes it can be hard learning maths at home because $\ldots \ldots \ldots \ldots \ldots \ldots \ldots$

2. Some of my favourite maths task when learning at home are.

3. The best thing about learning maths at home is

4. The best thing about learning $m$ aths at school is....

Figure 1. Open response items

engagement with mathematics learning at home. Parents/ carers were informed about the nature of the current study and were provided with a copy of the Student Engagement Survey via their child's teacher. If the parent/ carer agreed, their child was provided with the link to the survey, and completion of the survey was indicative of both the parents' and child's consent. All responses were anonymous and voluntary, however each child who completed the survey was given an opportunity to indicate their school and grade level. Given the understanding that the period punctuated by COVID-19 restrictions (including remote learning) was a challenging time for parents and students, the survey was designed not to be time-consuming nor onerous. The intention was that students might enjoy having an opportunity to explain how they felt about learning mathematics at home.

Fourteen multiple choice likert scale items were used to assess student engagement (see Tables 2-4). The items / statements were designed to elicit evidence of cognitive, emotional, social and behavioural engagement. Four open response questions were designed to provide information about what students enjoyed or found difficult about learning mathematics at home and to provide explanation of responses to the closed likert scale items. The open response questions are shown in Figure 1.

\section{Data Analysis}

Qualitative data (teacher interviews and students' written responses to free-format questions) was analysed thematically as outlined by Braun and Clarke (2006). Specifically, the following six steps were approximated: 1) familiarisation with the data, 2) generating initial codes, 3) searching for themes, 4) reviewing themes, 5) defining and naming themes, and, finally, 6) producing the report. However, the type of analysis (i.e., inductive or deductive) varied between the teachers' and students' data as outlined next.

\section{Teacher planning and challenges for remote learning}

A deductive approach (Braun \& Clarke, 2006) was used to create a detailed analysis of the data with respect to the first and second research questions. That is, the research questions determined the coding frame, and themes were identified that sought to explain how the teachers planned for and implemented remote learning in mathematics and the challenges they faced in this process. Also, school artefacts were collected and the online resources for students were explored to determine the types of mathematics learning activities that students engaged with.

\section{Student engagement}

All statements in the Student Engagement Survey were answered using a 4-point format (not at all true, not very true, sort of true, or very true). These were scored one to four respectively and the mean score out of four was calculated. Negative statements, such as "Learning maths at home is boring" were reverse coded (RC), so all scores range from 1 to 4 , with a higher score indicating a more positive engagement. The open response questions were analysed for themes using an inductive approach. That is, the analysis aimed to provide a "rich description of the data overall" (Braun \& Clarke, 2006, p. 84). A single response may be coded to more than one theme. The themes for the open response items were also used to provide depth and explanation for the students' quantitative results.

\section{FINDINGS}

The findings are structured around the four research questions. Themes that arose around each question are presented as sub-headings. Participant quotes were used selectively to add depth and clarity to the descriptions of each theme.

\section{Planning and Executing Remote Learning Opportunities in Mathematics}

In response to the first research question the following themes are described: the use of Information and Communication Technologies (ICT); the school's philosophy; mathematics manipulatives; and the development of mathematics learning experiences.

\section{The use of Information and Communication Technologies (ICT)}

In terms of ICT use, both schools utilised Google Classrooms as the platform for interacting with students. Initially, School A used Seesaw as a platform for 
feedback and reflection with students and parents, and as the teachers became more familiar with and utilised Loom, We Video, YouTube tutorials for uploading and creating videos, Zoom and Google Meet. To consolidate and reinforce the weekly maths assignments. School A regularly used Mathsonline. There was a lot of collegial discussion during weekly planning meetings to decide on the maths tasks. At School B the principal set up a "Learning from Home" page on their school website on which Toby would post the mathematics and literacy activities for each fortnight for Grades 3-6. The assistant principal at his school was the support person for families who had technical issues. Both schools provided links to many additional online mathematics activities, videos and resources.

Whilst both schools utilised ICT previous to COVID19, teachers and students were required to utilise programs that were not used previously to remote learning, for example, videoconferencing such as Zoom (to replace the classroom) and website pages for the posting of learning tasks. Digital platforms were more prominently used by teachers to provide students with feedback in comparison to verbal feedback in class or teacher notes in workbooks.

\section{The school's philosophy}

Both teachers described that their school's philosophy helped to direct their decisions about the expectations for home learning. Toby stated:

Our school's philosophy is very much about recognising the fact that each family has a different situation ... and not to put too much pressure on these families. We needed to make the learning opportunities open so families could make it work for them.

This philosophy underpinned their approach to limit the amount of time students needed to be in contact with teachers ("on average three times a week") and how often they were required to submit work ("one Numeracy and one Literacy related piece of work at the end of each week"). This was designed so that the requirements for students (and ultimately parents and carers) were "not particularly onerous". Similarly, Sapna described that students were not given deadlines for submitting work. The teachers provided recommendations for how much could be submitted but "that it was up to them to organise themselves". Another teacher from school A explained during an online podcast of a school meeting that they had attempted to make it clear to parents that not all learning needed to be online and that " $80 \%$ of the learning should occur offline". This occurred through investigations outside, playing games with family members or working independently on tasks.
Both teachers also highlighted that they intended to continue to create mathematics learning opportunities that were in keeping with their beliefs about how mathematics should be taught. Sapna noted that this meant maintaining an emphasis on challenge and inquiry, as well as drawing on particular resources, such as "Making it fun. Nothing Without Joy" (see Hall et al., 2010) and "Respecting children's learning styles - The 100 languages of Children" (see Edwards, Gandini, \& Forman, 1998). Toby also identified that engagement, open ended tasks, and challenge were important features of the mathematics learning opportunities they provided.

\section{Mathematics manipulatives}

Ensuring that each student had appropriate mathematics materials to participate in the learning experiences was an important consideration for each school. However, this seemed to be of greater concern for students in the younger grades than older students. Sapna explained that "learning packs" were hand delivered to the doorstep of families who did not have online access at the beginning of the remote learning time. These included workbooks and printed activity description documents. Toby also explained that the Grades F-2 teachers at his school developed maths kits with manipulatives for students, however he also explained that "this took 4-5 weeks to get rolled out". By contrast, in Grades 3-6 for which he was responsible, he aimed to develop activities with materials that were generally easy to access or that most homes might have.

\section{Mathematics learning experiences}

From analysing the interview transcripts and investigating the mathematics activities that were available on each school's website, it was clear that the mathematics experiences or tasks incorporated in each schools' program were extensive and varied. However, there were some underlying features about the activities that were similar for both schools.

These included:

- Giving students choice and therefore agency in what they did

- Tasks were intended to be engaging and relevant to students' interests

- Problem solving and investigations were included alongside more structured tasks

- Open ended tasks were prioritised

- Providing challenge was important

During the home learning period, each school delivered these learning activities using various arrangements. For example, School B posted on their Learning from Home Page, a "Menu of Learning Opportunities" which included activities for mathematics that were relevant for two weeks. The 
Grades F-2 students had one 'learning menu' and the Grades 3-6 students had another 'learning menu', so the tasks were intended to cater for a range of abilities. Students had complete control over both how many, and which, activities they undertook. These activities came from all teachers first submitting ideas into a Matrix (online space), then Toby collating them, selecting from these, adding to them, and subsequently developing the "menus" for all 3-6 students. While the intended tasks were similar to those that the students might experience face-to-face, this way of planning was a new approach for the teachers, to cater for the changes needed with home learning. Toby described the nature of the tasks as "a balanced approach" as they included problem solving activities, investigations, puzzles, games, and challenging tasks that were often connected mathematically. Toby reported that this balanced approach was typical practice for him and something that he chose to include in the learning menus.

School A endeavoured to maintain their usual way of planning a mathematics program which was around Learning Agreements. Prior to home learning, Learning Agreements were created around projects that covered a range of subjects. Sapna elaborated on an example:

One such project was "Travelling around Australia", and the children may have, for example, found out about aspects of the Great Barrier Reef. This led us to the big idea of Sustainability. For a maths workshop (onsite) on Area and Perimeter, instead of using new resources, we collected leaves of three different sizes from the garden, traced around them on a grid paper to learn about these mathematical concepts. The children would be given a range of tasks to do that were related to this topic (some of them being about mathematics) and some were extended tasks that were considered "provocations".

Sapna emphasised that all tasks were planned and implemented collaboratively with the team of teachers responsible for those year levels. She discussed how, during classroom learning (i.e., pre-COVID-19), when Learning Agreements were implemented face-to-face in the multi-age classes, the teachers each performed a different role. For example, one would roam around making sure resources were available, and students were on task, whilst another would sit in a predetermined space to observe students and take notes about what they know and could do. A third staff member would withdraw small groups for targeted teaching. Sapna noted at the end of a Learning Agreement the students would reflect on their learning, through writing about it or through individual or class discussions. However, in home learning, these ways of supporting students through small group work and targeted teaching were not possible. The reflection aspect was maintained during home learning through the use of Seesaw, but these were individually based and not shared in a class group as would have been the case when teaching face-to-face.

In summary, both teachers identified some features of teaching and learning mathematics in the home learning period that were important to them and their school. These were:

- Student agency: that is, that students have some choice and ownership over their learning

- Maintaining the school's philosophy for the teaching and learning of mathematics

- That the learning was engaging, relevant and appropriately challenging

- That the expectations on families was not too onerous

- The teachers worked collaboratively to design and deliver the remote learning program

\section{Challenges}

During the interviews both teachers described aspects of setting up and delivering the remote learning of mathematics that were challenging for themselves or their school community. Consequently, in response to the second research question, the following five themes were identified in one or both teachers' interviews.

1. Technology challenges for students, their families, and teachers

2. Lack of real-time feedback

3. Catering for all students' abilities and promoting independent work

4. Difficulties with assessment

5. Lack of social connectivity

Each of these themes related to challenges are now discussed in turn.

\section{Technology challenges for students, their families, and teachers}

Each teacher described early challenges with ensuring all students had access to a laptop and internet access. Sapna described the challenge of ensuring students and families could use the various online programs and getting them to participate, as well as managing the upskilling of staff to use the ICT. The lack of laptops and internet were met by either the school or the government providing laptops to those families who needed them, and the government providing dongles to those families without internet access. Sapna reported that some parents in their community were not familiar with the use of the technology or the platforms, and that in some cases, it took "2-3 weeks" to get most families participating in the online forum. She also acknowledged that her students "know some ICT skills 
but do not have enough to be independent." This may be a greater concern for Sapna as she taught younger students than Toby.

Sapna also explained that the teachers needed to upskill about various ICT programs, and they managed this by delegating each person to be the onsite expert for one program. For example, Sapna became the resident expert on WeVideo and how to film and edit herself and then put the video online for students. Toby explained that the assistant principal at his school provided the technical support for their families if it was requested and ensured the programs developed by the teachers were uploaded and accessible for students and parents.

\section{Lack of real-time feedback}

Sapna acknowledged that when working with students remotely it was difficult to give instant feedback in the same way as you might when teaching face-to-face. Sapna identified this as something they needed to do differently to their normal practice. She explained when checking students' work that "we gave feedback to almost everything but sometimes it was not instant". In terms of verbal feedback, she noted "if there were any misconceptions or alternate conceptions, amongst a concept we weren't there to clarify that on the spot. We weren't able to do conferencing with them .... and clarification of thinking". She also explained that this was one aspect of online learning she hoped they would improve should the students be learning from home again.

\section{Catering for all students' abilities and promoting independent work}

Toby described the challenge of designing tasks that would cater for a range of abilities and interests and trying to "envision how as many students as possible can access [the learning] as independently as possible". Making the learning accessible even for those who find mathematics difficult was important to him because he acknowledged that, as a parent himself, he understood the pressures of finding time to provide constant support. He identified that trying to "anticipate how [the learning] might go and cater for this in advance" was quite challenging and different to his normal classroom practice where it was possible to "make changes on the fly".

\section{Difficulties with assessment}

Both teachers described various ways in which they attempted to determine how well students were learning mathematics from home, but these avenues often posed difficulties. Toby explained that it was difficult to assess the work samples submitted by the students because "you do not know the level of support they got at home". However, he was able to obtain some data from the students' interactions on Mathletics (a Mathematics online program), as well as from their small group video conferencing opportunities. He also acknowledged that the small group conferencing was sometimes difficult to facilitate or to "see" each student every week.

Sapna explained that the students' work samples were used to assess their progress and that these were submitted through Google Classroom or sent to the teachers' emails. She acknowledged feeling that this meant "information was coming from everywhere". Also, some parents were not confident with taking photos of students' work or submitting them.

\section{Lack of social connectivity}

Toby described that it was "extremely difficult" and a "significant challenge" to find ways to engage students in the home learning space. He suggested one reason for this was that some students may be disabled by not having the social context that they would at school. He was also concerned that students who might struggle with learning mathematics at school may be less engaged at home, especially if they did not get support from an adult in their home environment.

Sapna had not explicitly indicated that engaging the students was a challenge, but she had concerns that there may be students who were not getting the support from home that would be needed. She also had concerns that the reflection stage of lesson that occurred in face-to-face teaching was not "community-based" in the online space. She described that in the whole-class discussions in a classroom setting "the students can spark each other's interest or give feedback to each other" and that replicating this online was not possible.

\section{Adjustments Made during the Second Phase of Remote Learning in Response to Challenges}

In response to the third research question whilst Sapna's school did not make any significant adjustments to the learning program as it was deemed comparatively successful in the first lockdown period, Toby's school made some adjustments with the aim of providing more synchronous sessions for students.

Following the first phase of remote learning Toby and the leadership team collected feedback from families, students and staff about their successes and challenges. This included a parent survey which included more than 100 responses. They used this information to make changes to their remote learning model and in doing so, were able to address some of the challenges previously outlined, although many persisted.

Specifically, the teaching and learning model was adjusted to place a greater emphasis on synchronous learning opportunities to complement the asynchronous learning and the 'learning menu' that were previously in place. During the second phase, students attended four small groups each week, two of which had a mathematical focus. This was a chance to engage 
Table 2. Frequency (percentage), and mean for each item related to students' cognitive engagement

\begin{tabular}{|c|c|c|c|c|c|c|c|}
\hline & $\mathrm{n}$ & $\begin{array}{l}\text { Not at } \\
\text { all true }\end{array}$ & $\begin{array}{l}\text { Not very } \\
\text { true }\end{array}$ & $\begin{array}{l}\text { Sort of } \\
\text { true }\end{array}$ & $\begin{array}{l}\text { Very } \\
\text { true }\end{array}$ & $\begin{array}{c}\text { Mean } \\
\text { out of } 4\end{array}$ & $\begin{array}{c}\text { Reverse } \\
\text { coded }\end{array}$ \\
\hline 1a. I am confident I can do the maths work at home & 36 & $1(3)$ & $3(8)$ & $15(42)$ & $17(47)$ & 3.3 & \\
\hline 1b. I can do most of the maths work by myself & 37 & $1(3)$ & $4(11)$ & $11(30)$ & $21(57)$ & 3.3 & \\
\hline $\begin{array}{l}\text { 1c. When I choose a maths task, I like to pick one that } \\
\text { challenges me }\end{array}$ & 36 & $2(6)$ & $9(25)$ & $18(50)$ & $7(19)$ & 2.8 & \\
\hline $1 \mathrm{~d}$. It is hard learning maths at home & 36 & $10(28)$ & $9(25)$ & $12(33)$ & $5(14)$ & 2.3 & 2.7 \\
\hline $\begin{array}{l}\text { 1e. When I choose a maths task, I like to pick one that is } \\
\text { easy to do }\end{array}$ & 37 & 7 (19) & $14(38)$ & $12(32)$ & $4(11)$ & 2.5 & 2.6 \\
\hline
\end{tabular}

students with mathematical discussion and thinking, with a focus on connecting these experiences to the asynchronous learning opportunities.

Part of this restructure was about providing additional social learning opportunities and to increase student engagement in their mathematical learning, with an emphasis on playing mathematical games that supported concepts related to students' asynchronous learning. Toby noted, however, that the nature of online learning meant that much of the mathematical discussion was guided by and went 'through' the teacher. These two weekly online maths groups meant that the vast majority of students engaged with some mathematical learning every week. Although some students did not submit work in both phases of remote learning, Toby indicated there was very high attendance at these groups. This suggests that almost all students were keen to engage in mathematical activities in realtime with peers in a teacher-facilitated, synchronous environment, even if they were less inclined to undertake mathematical tasks independently.

Toby discussed how the 'learning menu' which previously provided the majority of learning opportunities, was scaled back. Students were provided with a daily, differentiated mathematical learning task through the online platform Google Classroom, with the same 'balanced approach' to learning opportunities guiding the design of activities. Toby worked with a small team of 3-6 teachers to develop these activities. In this phase, teachers, to support other learning tasks, also created some explicit instructional videos. The modified learning menu only included two mathematical tasks (general problem solving or challenging tasks) to complement the learning tasks on Google Classroom.

The synchronous learning context also provided some more authentic formative assessment opportunities compared with the first phase, for example through the use of number talks to explore student understanding of various strategies. However, Toby noted that similar challenges around assessment were still apparent.

The new structure also sought to address some of the challenges around feedback. With more synchronous learning, students received more immediate feedback from teachers, but this was limited to the 40 minutes of online mathematical learning. Through the use of
Google Classroom, teachers provided comments on all student work submitted. There were still challenges around the timeliness and value of this feedback, and it lacked the richness of real-time verbal dialogue between student and teacher. Toby discussed how the model enabled teachers to be somewhat more responsive to students' learning needs, specifically through guidance around learning tasks either using the comments tool on Google Classroom or during discussions in small groups. However, this was often limited to the more proactive learners.

In summary, School B prioritised synchronous learning during the second phase of remote learning to provide more opportunities for teachers to provide students with peer and teacher interactions, real time feedback and better assessment of student progress and understandings. In essence, Toby tried to replicate a live classroom learning environment as much as possible without compromising the selection of tasks to suit the inquiry-based learning philosophy.

\section{Students' Engagement during 'At Home' Learning}

Given the importance of student engagement for student learning and achievement (Finn \& Zimmer, 2012) and the concerns by teachers nationally (Flack et al., 2020) and internationally (Reich et al., 2020) that students may be less motivated to participate in their academic work during learning at home, our study aimed to measure student engagement in their mathematics learning. An online anonymous survey completed by 37 primary students from the two case study schools was used to provide some evidence of their engagement. In response to the fourth research question, the results in terms of students' cognitive, emotional, and behavioral/social engagement are discussed separately. The items in each table of data have been sorted by mean from the 'most positive' response to the 'least positive'. This order does not represent the order that they occurred in the online survey.

\section{Cognitive engagement}

Table 2 shows results for students' responses to items related to cognitive engagement when learning mathematics at home. The mean indicates that for all statements the students were at least moderately 
Table 3. Frequency (percentage), and mean for each item related to students' emotional engagement

\begin{tabular}{|c|c|c|c|c|c|c|c|}
\hline & $\mathrm{n}$ & $\begin{array}{l}\text { Not at } \\
\text { all true }\end{array}$ & $\begin{array}{l}\text { Not very } \\
\text { true }\end{array}$ & $\begin{array}{l}\text { Sort of } \\
\text { true }\end{array}$ & $\begin{array}{l}\text { Very } \\
\text { true }\end{array}$ & $\begin{array}{c}\text { Mean } \\
\text { out of } 4\end{array}$ & $\begin{array}{c}\text { Reverse } \\
\text { coded }\end{array}$ \\
\hline 2a. Learning maths at home is fun & 36 & $3(8)$ & $7(19)$ & $20(56)$ & $6(17)$ & 2.9 & \\
\hline $2 \mathrm{~b}$. The maths I learn at home is interesting & 37 & $2(5)$ & $8(22)$ & $19(51)$ & $8(22)$ & 2.9 & \\
\hline 2c. Learning maths at home is boring & 35 & $11(31)$ & $12(34)$ & $7(20)$ & $5(14)$ & 2.3 & 2.8 \\
\hline $2 \mathrm{~d}$. I am happy when doing maths work at home & 22 & $5(23)$ & $1(5)$ & $12(55)$ & $4(18)$ & 2.7 & \\
\hline $\begin{array}{l}\text { 2e. When I have a choice, I usually choose to do a maths } \\
\text { task rather than another subject }\end{array}$ & 37 & $8(22)$ & $13(35)$ & $12(32)$ & $4(11)$ & 2.4 & \\
\hline
\end{tabular}

Table 4. Frequency (percentage), and mean for each item related to students' behavioral and social engagement

\begin{tabular}{|c|c|c|c|c|c|c|c|}
\hline & $\mathrm{n}$ & $\begin{array}{l}\text { Not at } \\
\text { all true }\end{array}$ & $\begin{array}{l}\text { Not very } \\
\text { true }\end{array}$ & $\begin{array}{c}\begin{array}{c}\text { Sort of } \\
\text { true }\end{array} \\
\end{array}$ & $\begin{array}{l}\text { Very } \\
\text { true }\end{array}$ & $\begin{array}{c}\text { Mean } \\
\text { out of } 4\end{array}$ & $\begin{array}{c}\text { Reverse } \\
\text { coded }\end{array}$ \\
\hline $\begin{array}{l}\text { 3a. Someone at home helps me with my maths work } \\
\text { when I am stuck }\end{array}$ & 37 & $2(5)$ & $3(8)$ & $13(35)$ & $19(51)$ & 3.3 & \\
\hline 3b. I do all the maths work my teacher wants me to do & 37 & $4(11)$ & $2(5)$ & $8(22)$ & $23(62)$ & 3.2 & \\
\hline $\begin{array}{l}\text { 3c. My teacher lets me know how well I am doing the } \\
\text { maths activities at home }\end{array}$ & 37 & $2(5)$ & $6(16)$ & $15(41)$ & $14(38)$ & 3.0 & \\
\hline 3d. I miss doing maths with my friends at school & 36 & $0(0)$ & $3(8)$ & $7(19)$ & $26(72)$ & 3.5 & 1.4 \\
\hline
\end{tabular}

engaged, with all means being above 2.5 out of 4 . Overall, they felt confident they could do the maths work at home, could do the work independently, and importantly more students preferred to choose a challenging task than an easy task.

However, $47 \%(n=17)$ chose sort of true or very true that learning maths at home was hard (Item 1d). The open response item Sometimes it can be hard learning maths from home because.... was examined to determine the reasons these 17 students gave for nominating that it was hard. Approximately half $(n=8)$ indicated a reason that represented a lack of cognitive engagement. Seven students indicated that they were not getting the help they desired from an adult, such as the teacher or a parent (e.g., GR6 "My teachers can't explain it in person"; GR2 "My mum is not a math teacher and we sometimes get stuck in a task"). One suggested they did not understand some of the work (GR6 "I don't understand some stuff"). However, nine students indicated learning maths at home was hard for behavioural, social, or emotional reasons. Five students indicated that they lacked the appropriate attention needed to stay on task (e.g., Behavioural engagement GR6 "I sometimes get carried away and do things other than maths"). Two indicated an emotional response (e.g., GR6 "It isn't enjoyable"), and two had a social reason (e.g., GR6 "I don't get to work with my friends"). Therefore, item 1d assessed a range of engagement types, however a lack of cognitive engagement was the most common explanation behind why learning mathematics at home was hard.

\section{Emotional engagement}

Table 3 shows results for students' responses to items related to their emotional engagement when learning mathematics at home. The mean indicates that for all statements the students were at least moderately engaged, with all means being above 2.4 out of 4 . More than two-thirds of the students chose either sort of true or very true for items that suggested learning maths at home was fun, interesting, or not boring, and that they were happy when doing maths at home (Items 2a-d). However, this also indicates that around one third of students had a negative emotional response to learning mathematics at home.

\section{Behavioral and social engagement}

Students were surveyed regarding their effort with completing all tasks expected of them (Item 3b), and their perception of teachers' and parents' actions that are likely to promote their behavioral engagement, such as support when 'stuck' (Item 3a) and teacher feedback (Item 3c) (see Table 4). These three items obtained high means (at or above three). These results indicate that most students believed they were doing all the maths work that they were expected to do, that they were getting the home support that they needed when they were stuck, and that their teacher was keeping them informed with their progress.

Given the identified risk of meeting students' social needs and the lack of social interaction during remote learning (Flack et al., 2020) one item was included in the survey to determine the students' feelings when learning maths at home without friends as compared to being at school with their friends (Item 3d). This statement was reverse coded so that a high mean would represent a positive response. That is the higher the mean the lower the negative effect of not being able to work with their friends or peers. This item had the lowest mean of all statements indicating that the experience of not being able to do mathematics with their friends was having a negative effect on most students. The lack of social connectivity when learning mathematics was echoed in the data from the open response items. The most common category ( $58 \%$ of students) indicated the best things about learning maths at school is learning or 
doing it with friends or peers (e.g., GR5 “Doing it with my friends and talking about it with them and my teacher"). Three additional students also indicated that they could learn from their friends or peers (e.g., GR5 "My classmates can help me when I am stuck"). Five students reported that it was hard learning maths at home because they had no friends to work with (e.g., GR6 "There's usually no one to play maths tasks with me"; GR6 "Very isolated and by myself").

\section{Open Response Survey Items}

The four open response items were analysed for themes to elaborate students' engagement with learning mathematics at home and to make some tentative connections between the schools' implementation of their 'at home' mathematics programs and the students' self-reported engagement. Only the most common themes for each open response item will be described. Given the small sample size there has been no attempt to compare responses of students from lower versus upper grades. Examples of responses are illustrative and not indicative of that grade level. When possible, an example was chosen from a lower and an upper primary grade.

The following five main themes occurred in response to Sometimes it can be hard learning maths at home because. They were (with the frequency of responses in parentheses and illustrative quotes):

- Lack of help from teachers or parents (12) - GR5 "I can't ask my teacher for help like I can in class"; GR2 "My mum is not a math teacher and we sometimes we get stuck in a task"

- More distracted or less focused (10) - GR6 "I sometimes get carried away and do things other than maths."; GR2 "I get distracted"

- A negative emotional response (5) - GR6 “It isn't enjoyable"; GR2 "It's not fun"

- Lack of understanding (5) - GR6 “I don't understand some stuff"; GR1 "I don't get it"

- Lack of social connectivity (5) - GR6 "Very isolated and by myself"; GR2 "Just missing friends"

The difficulties that the students have reported align with teachers' views in the current study and other studies, that the home environment may not be providing the support necessary for academic learning and that the students' motivation and social needs may be lacking.

The following five main themes occurred in response to The best thing about learning maths at home is. They were (with the frequency of responses in parentheses and illustrative quotes):

- Greater choice of when to do tasks and for how long (9) - GR5 “I can take it at my own speed, and if I'm stuck I can re-watch the video, or read the instructions, again and again until I get it."; GR2 "I can take my own time to do it"

- The tasks or activities (7) - GR5 "Playing fun games that my teacher taught us"; GR1 "I can engage in online math challenges"

- Support from family members (4) - GR6 "My mum can help me"; GR2 "My mom (sic) helping me with maths and we make it fun together and it's easier to learn then"

- The choice of tasks (4) - GR6 "I like the independence to choose what tasks I do and when I do them"; GR4 "Having different challenges to challenge me at my own level".

The positive aspects that students have reported align with the schools' philosophy about teaching mathematics and the decisions the teachers made when selecting tasks, such as: the students should have agency to choose tasks of interest to them, that tasks are engaging and relevant, and that tasks are appropriately challenging.

The following five main themes occurred in response to The best thing about learning maths at school is:

- Doing/learning maths with peers (21) - GR5 "Doing it with my friends and talking about it with them and my teacher"; GR2 "Being with my friends"

- The availability of the teacher (8) - GR6 "I have a teacher around if I really need some help"; GR5 "I can ask my teacher questions straight away"

- Support from peers (3) - GR6 "Group or peer learning helps to bounce ideas off one another"

- The tasks or activities (3) - GR5 "That you have super interesting tasks. You get to play games, and do stuff with other people, but at home we don't play games"

As outlined previously, Australian teachers indicated their concern for students' social needs (Flack et al., 2020). These data suggest social interactions with teachers, friends, and peers contributes to students' learning and understanding of the mathematics.

When learning mathematics at home the favourite tasks listed by most students were games or puzzles $(n=8)$. There was a large range of tasks described indicating the variety of preferences for students. Some indicated mathematical diagrams such as charts and graphs $(n=6)$ and others named specific content areas such as Addition and/or Subtraction $(n=4)$ or Multiplication and/or Division ( $\mathrm{n}=4)$. Only two students suggested they could not think of a mathematics task they enjoyed.

\section{DISCUSSION AND CONCLUSIONS}

Mathematical inquiry learning involves supporting students to develop approaches to thinking and problem 
solving within classroom environments characteristics by rich mathematical discussion, conjecture and argumentation (Cobb, Yackel, \& Wood, 1992). The teacher plays a facilitative role, focussed on scaffolding student thinking and supporting student autonomy (Fielding-Wells \& Makar, 2008). The students in this study seem to have developed good independent learning skills at school that have been transferrable to the home learning situation. When responding to the cognitive engagement survey questions, the students said that they felt confident to complete the maths work at home, they could do the work independently, and they preferred to choose a challenging task rather than an easy task. This is consistent with previous research suggesting that, for many students, mathematical challenge is often experienced as something that is enjoyable and worth seeking out (Russo \& Hopkins, 2017; Russo \& Minas, 2020; Russo \& Russo, 2020).

Inquiry learning promotes students to construct knowledge for themselves however, teachers still need to attend to the interpretations of students, and provide support on a 'just in time' basis (Bransford, Brown, \& Cocking, 2000; Fielding-Wells \& Makar, 2008). The inability for teachers to provide real time feedback was something that both teachers in this study described as a challenge during home learning and was also felt by the students who described their frustration when their teachers and parent(s) were unavailable or unable to assist them. This may have led to students coming 'off task' and distracted or behaviourally disengaged (Kong, Wong \& Lam, 2003). Given that inquiry-based approaches involve learning through dialogue centred on a previous mathematical exploration (Sullivan et al., 2020), it is possible that the lack of opportunity for synchronous feedback was particularly problematic for the cognitive engagement of students in our two study schools, given their focus on inquiry-based pedagogies. This is especially true since teachers like Toby and Sapna adopted an approach to limit the amount of time students needed to be in contact with teachers ("on average three times a week"), in order to mitigate against teacher burnout and to avoid placing too much pressure on students and parents. Although Toby's school made adjustments for the second lockdown period to enable more synchronous interactions between students, their peers and teachers, in comparison to a regular classroom environment, there were still far fewer opportunities for socially facilitated learning. Other studies have also identified the lack of a teacher-facilitated, synchronous learning environment as a significant barrier to adopting inquiry-based pedagogical approaches in a remote learning context (Russo et al., 2021). Teachers may need to consider maximising conferencing through ICT platforms in future home learning situations if inquiry learning is to be continued and further supported.

Social interaction with peers during group work in inquiry learning is essential for students' cognitive development (Yackel et al., 1991). This is further supported by research suggesting that opportunities to learn from peers and work collaboratively is an aspect of learning mathematics through inquiry that is valued by students (Russo \& Minas, 2020). The absence of peer support and collaborative work was the most significant challenge described by the students in this study, and perhaps the most notable barrier to establishing sociomathematical norms conducive to inquiry-based learning in a remote learning setting. This was the case despite Toby's school making adjustments specifically to enhance the social aspects of learning during the second lockdown. It is not immediately obvious that this particular challenge can be easily overcome by more effective utilisation of technology, particularly within a primary school context where peer-to-peer interactions through interactive platforms such as Google Classrooms and Zoom are generally teacher mediated. However, given that inquiry learning that involves challenging tasks seem to continue to engage and interest students during remote learning, it appears to be worthwhile for teachers to explore technology that could be used to provide more opportunities for virtual, social interaction to support peer-to-peer learning and collaborative mathematical work (Yackel et al., 1991).

Although this study has limitations in terms of the selective nature of the sample, as a case study it served its purpose. In particular, it was deemed important for the sociocultural context of each teacher participant's school to be recognised; therefore, a qualitative approach was adopted. However, it should be acknowledged that including a larger sample of schools would have enabled this study to be conducted across different contexts achieving greater teacher and student diversity, and potentially making the findings more generalisable. Furthermore, considering a larger range of teacher pedagogies and strategies to engage students when learning mathematics from home would have enabled us to map a more extensive range of practices that teachers with different teaching philosophies adopted.

This study has shown that teachers Toby and Sapna were able to continue to deliver inquiry-based mathematics learning experiences to their students despite the challenges. Our study has important implications for practising primary-school teachers pursuing inquiry-based learning in remote learning contexts. First, there should be an emphasis on the quality of the mathematical opportunities provided, rather than the quantity of tasks offered; too much choice can overwhelm. By scaling back the 'learning menu', Toby seems to have followed the advice of Finkel (2020) and Drane et al. (2020) not to overload students and their families. Second, students clearly value opportunities to work synchronously alongside peers with teachers providing real-time feedback. Future efforts to pursue inquiry-based learning in a remote learning environment need to utilise technology to facilitate such 
experiences, rather than expecting students to pursue tasks or investigations in relative isolation, relying on asynchronous feedback mechanisms (e.g., posting work on a digital platform).

Author contributions: All authors have sufficiently contributed to the study, and agreed with the results and conclusions.

Funding: No funding source is reported for this study.

Declaration of interest: No conflict of interest is declared by authors.

\section{REFERENCES}

Alfieri, L., Brooks, P. J., Aldrich, N. J., \& Tenenbaum, H. R. (2011). Does discovery-based instruction enhance learning? Journal of Educational Psychology, 103(1), 1-18. https:/ / doi.org/10.1037/a0021017

Angus, M., McDonald, T., Ormond, C., Rybarcyk, R., Taylor, A., \& Winterton, A. (2009). Trajectories of classroom behaviour and academic progress: A study of engagement. Edith Cowan University. http:/ / www.bass.edu.au/files/5413/9925/8294/ Pipeline_Report_Dec_2009.pdf

Bempechat, J., \& Shernoff, D. J. (2012). Parental influences on achievement and student motivation. In S. L. Christenson, A. L. Reschly, \& C. Wylie (Eds.), Handbook of research on student engagement (pp. 315-342). Springer. https://doi.org/10.1007/ 978-1-4614-2018-7_15

Bishop, A. J., \& Kalogeropoulos, P. (2015). (Dis)engagement and exclusion in mathematics classrooms - Values, labelling and stereotyping. In A. Bishop, H. Tan, \& T. N. Barkatsas (Eds.), Diversity in mathematics education (pp. 193-217). Springer. 05978-5_12

Blackburn, B. R. (2020). Rigor in the Remote Learning Classroom: Instructional Tips and Strategies. Routledge.

https://doi.org/10.4324/9781003107484

Boston, M. D., \& Smith, M. S. (2009). Transforming secondary mathematics teaching: Increasing the cognitive demands of instructional tasks used in teachers' classrooms. Journal for Research in Mathematics Education, 40(2), 119-156. http:/ / www.jstor.org/stable/40539329

Bransford, J. D., Brown, A. L., \& Cocking, R. R. (2000). How people learn (Vol. 11). National academy press.

Braun, V., \& Clarke, V. (2006). Using thematic analysis in psychology. Qualitative Research in Psychology, 3(2), 77-101.

https:/ / doi.org/10.1191/1478088706qp063oa

Clarke, D., Roche, A., Cheeseman, J., \& Sullivan, P. (2014). Encouraging Students to Persist When Working on Challenging Tasks: Some Insights from Teachers. Australian Mathematics Teacher, 70(1), 311.
Cobb, P., Yackel, E., \& Wood, T. (1992). A constructivist alternative to the representational view of mind in mathematics education. Journal for Research in Mathematics Education, 23(10), 2-33. https:/ / doi.org/10.5951/jresematheduc.23.1.0002

Drane, C., Vernon, L., \& O'Shea, S. (2020). The impact of 'learning at home' on the educational outcomes of vulnerable children in Australia during the COVID-19 pandemic. Literature Review prepared by the National Centre for Student Equity in Higher Education, Curtin University, Australia.

Edwards, C., Gandini, L., \& Forman, G. (Eds.) (1998). The hundred languages of children. The Reggio Emilia Approach-Advanced reflections (2nd ed.). JAI Press.

Fielding-Wells, J., \& Makar, K. (2008). Student (dis)engagement in mathematics. In Paper presented at the Annual Conference of the Australian Association for Research in Education, Brisbane, Australia. http:/ / www.aare.edu.au/08pap/mak08723.pdf

Fielding-Wells, J., O'Brien, M., \& Makar, K. (2017). Using expectancy-value theory to explore aspects of motivation and engagement in inquiry-based learning in primary mathematics. Mathematics Education Research Journal, 29(2), 237-254. https: / / doi.org/10.1007/s13394-017-0201-y

Finkel, A. (2020). Learning outcomes online vs inclass education. Rapid Research Information Forum. https://www.science.org.au/covid19/learningoutcomes-online-vs-inclass-education

Finn, J. D., \& Zimmer, K. S. (2012). Student engagement: What is it? Why does it matter? In S. L. Christenson, A. L. Reschly, \& C. Wylie (Eds.), Handbook of research on student engagement (pp. 97-131). Springer. https: / / doi.org/10.1007/978-1-4614-2018-7_5

Flack, C. B., Walker, L., Bickerstaff, A., Earle, H., \& Margetts, C. (2020). Educator perspectives on the impact of COVID-19 on teaching and learning in Australia and New Zealand. Pivot Professional Learning.

Fredricks, J. A., Blumenfeld, P. C., \& Paris, A. H. (2004). School engagement: Potential of the concept, state of the evidence. Review of Educational Research, 74, 59-109. https:/ / doi.org/10.3102/00346543074001059

Hall, K., Horgan, M., Ridgway, A., Murphy, R., Cunneen, M., \& Cunningham, D. (2010). Loris Malaguzzi and the Reggio Emilia experience. Continuum International Publishing Group.

Hamilton, L. S., Kaufman, J. H., \& Diliberti, M. (2020). Teaching and leading through a pandemic: key findings from the American Educator Panels Spring 2020 COVID-19 Surveys. Rand Corporation. https:/ / doi.org/10.7249/RRA168-2

Hancock, K. J., \& Zubrick, S. R. (2015). Children and young people at risk of disengagement from school: Literature 
review. Commissioner for children and young people, University of Western Australia.

Kong, Q. P., Wong, N. Y., \& Lam, C. C. (2003). Student engagement in mathematics: Development of instrument and validation of construct. Mathematics Education Research Journal, 15(1), 4-21. https:/ / doi.org/10.1007/bf03217366

Makar, K., \& Fielding-Wells, J. (2018). Shifting more than the goal posts: developing classroom norms of inquiry-based learning in mathematics. Mathematics Education Research Journal, 30(1), 53-63. https: / / doi.org/10.1007/s13394-017-0215-5

Makar, K., Bakker, A., \& Ben-Zvi, D. (2015). Scaffolding norms of argumentation-based inquiry in a primary mathematics classroom. ZDM, 47(7), 11071120. https:/ / doi.org/10.1007/s11858-015-0732-1

Reich, J., Buttimer, C. J., Coleman, D., Colwell, R., Faruqi, F., \& Larke, L. R. (2020, July). What's lost, what's left, what's next: Lessons learned from the lived experiences of teachers during the pandemic. https://doi.org/10.35542/osf.io/8exp9

Russo, J. A., \& Russo, T. (2019). Teacher interest-led inquiry: unlocking teacher passion to enhance student learning experiences in primary mathematics. International Electronic Journal of Mathematics Education, 14(3), 701-717. https://doi.org/10.29333/iejme/5843

Russo, J., \& Hopkins, S. (2017). Student reflections on learning with challenging tasks: 'I think the worksheets were just for practice, and the challenges were for maths'. Mathematics Education Research Journal, 29(3), 283-311. https: / / doi.org/10.1007/s13394-017-0197-3

Russo, J., \& Minas, M. (2020). Student Attitudes Towards Learning Mathematics Through Challenging, Problem Solving Tasks: "It's so Hard-in a Good Way". International Electronic Journal of Elementary Education, 13(2), 215-225. https://doi.org/10.26822 /iejee.2021.185

Russo, J., \& Russo, T. (2020). Movies through a mathematical lens. Australian Primary Mathematics Classroom, 25(1), 20-26.

Russo, J., Bobis, J., Downton, A., Livy, S., \& Sullivan, P. (2021). Primary Teacher Attitudes towards Productive Struggle in Mathematics in Remote Learning versus Classroom-Based Settings. Education Sciences, 11(2), 35, https:// doi.org/10.3390/educsci11020035

Russo, J., Minas, M., Hewish, T., \& McCosh, J. (2020). Using Prompts to Empower Learners: Exploring Primary Students' Attitudes Towards Enabling Prompts When Learning Mathematics Through Problem Solving. Mathematics Teacher Education and Development, 22(1), 48-67.
Ryan, R. M., \& Deci, E. L. (2000). Intrinsic and extrinsic motivations: Classic definitions and new directions. Contemporary Educational Psychology, 25(1), 54-67. https://doi.org/10.1006/ceps.1999. 1020

Saunders-Stewart, K. S., Gyles, P. D., \& Shore, B. M. (2012). Student outcomes in inquiry instruction: A literature-derived inventory. Journal of Advanced Academics, 23(1), 5-31. https://doi.org/10.1177/ $1932202 \times 11429860$

Shernoff, D. J. (2013). Optimal learning environments to promote student engagement. Springer. https: / / doi.org/10.1007/978-1-4614-7089-2

Skinner, E. (2016). Engagement and disaffection as central to processes of motivational resilience and development. In K. R. Wentzel \& D. B. Miel (Eds.), Handbook of motivation at school (2nd Ed.), (pp. 145168). Routledge.

Skinner, E. A., \& Belmont, M. J. (1993). Motivation in the classroom: Reciprocal effect of teacher behavior and student engagement across the school year. Journal of Educational Psychology, 85(4), 571-581. https:/ / doi.org/10.1037/0022-0663.85.4.571

Stein, M. K., Engle, R. A., Smith, M. S., \& Hughes, E. K. (2008). Orchestrating productive mathematical discussions: Five practices for helping teachers move beyond show and tell. Mathematical thinking and learning, 10(4), 313-340. https://doi.org/ $10.1080 / 10986060802229675$

Sullivan, P., \& Mornane, A. (2014). Exploring teachers' use of, and students' reactions to, challenging mathematics tasks. Mathematics Education Research Journal, 26(2), 193-213. https://doi.org/10.1007/ s13394-013-0089-0

Sullivan, P., Bobis, J., Downton, A., Feng, M., Hughes, S., Livy, S., McCormick, M., \& Russo, J. (2020). Threats and opportunities in remote learning of mathematics: implication for the return to the classroom. Mathematics Education Research Journal, 32(3), 551-559. https://doi.org/10.1007/s13394020-00339-6

Thomson, S. (2020). What PISA tells us about our preparedness for remote learning, Teacher Magazine. https:/ / www.teachermagazine.com.au/ columnists / sue-thomson/what-pisa-tells-usabout-our-preparedness-for-remote-learning

Thomson, S., De Bortoli, L. J., \& Buckley, S. (2014). PISA 2012: How Australia measures up. Australian Council for Educational Research. https://research.acer. edu.au / cgi / viewcontent.cgi?article=1015\&context $=$ ozpisa

USA TODAY, \& Ipsos. (2020). Online polls of $505 \mathrm{~K}-12$ teachers and 403 parents with at least one child in K-12 taken May 18-21. https://www.usatoday.com/ story / news/education/2020/05/26/coronavirus- 
schools-teachers-poll-ipsos-parents-fallonline/5254729002/

Yackel, E., \& Cobb, P. (1996). Sociomathematical norms, argumentation, and autonomy in mathematics. Journal for Research in Mathematics Education, 27(4), 458-477. https:/ / doi.org/10.2307/749877
Yackel, E., Cobb, P., \& Wood, T. (1991). Small-group interactions as a source of learning opportunities in second-grade mathematics. Journal for Research in Mathematics Education, 22(5), 390-408. https:/ / doi.org/10.2307/749187

\section{http://www.ejmste.com}

